\title{
Easy access to heterobimetallic complexes for medical imaging applications via microwave-enhanced cycloaddition
}

\author{
Nicolas Desbois, Sandrine Pacquelet, Adrien Dubois, Clément Michelin \\ and Claude P. Gros*
}

\author{
Full Research Paper \\ Address: \\ Université de Bourgogne Franche-Comté, ICMUB (UMR CNRS \\ 6302), 9 Avenue Alain Savary, BP 47870, 21078 Dijon Cedex, France \\ Email: \\ Claude P. Gros* - claude.gros@u-bourgogne.fr \\ * Corresponding author \\ Keywords: \\ click chemistry; corrole; DOTA; microwave; NOTA; porphyrin
}

\author{
Beilstein J. Org. Chem. 2015, 11, 2202-2208. \\ doi:10.3762/bjoc. 11.239 \\ Received: 24 July 2015 \\ Accepted: 25 October 2015 \\ Published: 17 November 2015 \\ Associate Editor: I. Marek \\ (c) 2015 Desbois et al; licensee Beilstein-Institut. \\ License and terms: see end of document.
}

\begin{abstract}
The $\mathrm{Cu}(\mathrm{I})$-catalysed Huisgen cycloaddition, known as "click" reaction, has been applied to the synthesis of a range of triazolelinked porphyrin/corrole to DOTA/NOTA derivatives. Microwave irradiation significantly accelerates the reaction. The synthesis of heterobimetallic complexes was easily achieved in up to $60 \%$ isolated yield. Heterobimetallic complexes were easily prepared as potential MRI/PET (SPECT) bimodal contrast agents incorporating one metal (Mn, Gd) for the enhancement of contrast for MRI applications and one "cold" metal $(\mathrm{Cu}, \mathrm{Ga}, \mathrm{In})$ for future radionuclear imaging applications. Preliminary relaxivity measurements showed that the reported complexes are promising contrast agents (CA) in MRI.
\end{abstract}

\section{Introduction}

Magnetic resonance imaging (MRI), positron emission tomography (PET) or single photon emission computed tomography (SPECT) are actually the most commonly used imaging modalities. MRI provides high-resolution (at the submillimeter level), but is limited by its low sensitivity. Conversely, PET and SPECT imaging are more sensitive methods but they both suffer from low anatomical resolution. As one single modality is usually not sufficient to obtain all the necessary information, multimodal imaging appears to be a promising solution. The advantages of one technique can easily be combined with the advantages of another one, whilst reducing, at the same time, the disadvantages of both. PET and MRI are largely comple- mentary techniques and combination of both would certainly lead to a 'marriage of convenience' [1].

Our group previously reported the synthesis of porphyrinDOTA-like scaffolds for multimodal imaging [2,3]. We were interested in heterobimetallic complexes incorporating both gadolinium and copper atoms. We now want to report new multimodal porphyrinoids-DOTA-like agents incorporating different metal ions, e.g., $\mathrm{Mn}, \mathrm{Ga}$, In, etc. of potential interest in medical imaging. Many examples of bimodal agents have been recently reported in the literature [4-6]. However, most of the bimodal agents were prepared for a specific application. To our 
part, our idea was to develop a toolbox of different dyads for further coordination of different types of metals, the easy and fast assembly of two polyazamacrocycles providing easy access to new bimodal probes. Depending upon the desired application, it could allow choosing one paramagnetic metal for MRI and one radiometal for application in PET. The 'Huisgen' $\mathrm{Cu}$ (I)-catalyzed cycloaddition appears to be a good answer to access to such bimodal agents [7]. For example, Caravan and co-workers have described an MRI-PET agent using a copper(I)-catalyzed Huisgen cycloaddition [8]. To prepare new multimodal agents, we have chosen two porphyrinoid derivatives that are easy to prepare in only a few steps: an azidocorrole 1 [9] and an azidoporphyrin 2 [10] (Figure 1).

Porphyrins and corroles display interesting properties in terms of metal complexation of, e.g., transition metals. We have selected two commercial available alkynes e.g. a propargylDOTA-tris $\left(t\right.$-Bu)ester and a propargyl-NOTA $(t-\mathrm{Bu})_{2}$. Indeed, 1,4,7,10-tetraazacyclododecane-1,4,7,10-tetraacetic acid (DOTA, 3) and 1,4,7-triazacyclononane-1,4,7-triacetic acid (NOTA, 4) are well-known to form highly stable Gd(III) and $\mathrm{Ga}$ (III) complexes and they are intensely studied as chelates for many imaging modalities.

To further demonstrate the versatility of the selected chelating agents, we have chosen two metals for MRI applications (Mn and $\mathrm{Gd}$ ) and three metals ("cold" models of radionuclide) for possible nuclear imaging applications (e.g., $\mathrm{Cu}, \mathrm{Ga}, \mathrm{In}$ ).
Gadolinium. There have been many examples in recent years of targeted contrast agents prepared via the use of an amide side arm Gd-DOTA [11]. In the case of porphyrin derivatives, gadolinium complexes are unstable (a fast demetallation reaction is usually observed) in many common solvents like toluene, methylene chloride, chloroform or methanol [12] thus MRI applications of Gd-porphyrins are difficult to envisage.

Manganese. The design of gadolinium complex did not fully eliminate the risk of in vivo release and accumulation which is a common problem implicated in nephrogenic systemic fibrosis. A possible solution is to replace Gd(III) with a more biocompatible metal species, ideally displaying higher relaxivity at high fields. Manganese is a promising candidate with limited toxicity at low concentrations. Up to now and so far to our knowledge, no Mn-DOTA/NOTA complexes have found application as contrast agents for MRI. Indeed, manganese complexes of DOTA/NOTA macrocycles are thermodynamically less stable than other transition metal ions or $\mathrm{Gd}^{3+}$ analogues [13]. Over the years and to overcome this problem, a variety of $\mathrm{Mn}$ (III) porphyrins have been prepared and investigated for their potential use as MRI contrast agent $[14,15]$.

Copper-64. Despite the emerging recognition of ${ }^{64} \mathrm{Cu}$ as a suitable radioisotope in positron emitting tomography (PET) imaging $\left(t_{1 / 2}=12.7 \mathrm{~h}, \beta^{+}: 17.4 \%, E_{\beta+\max }=656 \mathrm{keV} ; \beta^{-}: 39 \%\right.$, $\left.E_{\beta \text {-max }}=573 \mathrm{keV}\right)$, there is actually only few examples of the association of ${ }^{64} \mathrm{Cu}^{2+}$-labeled NOTA/DOTA [16,17] and por-
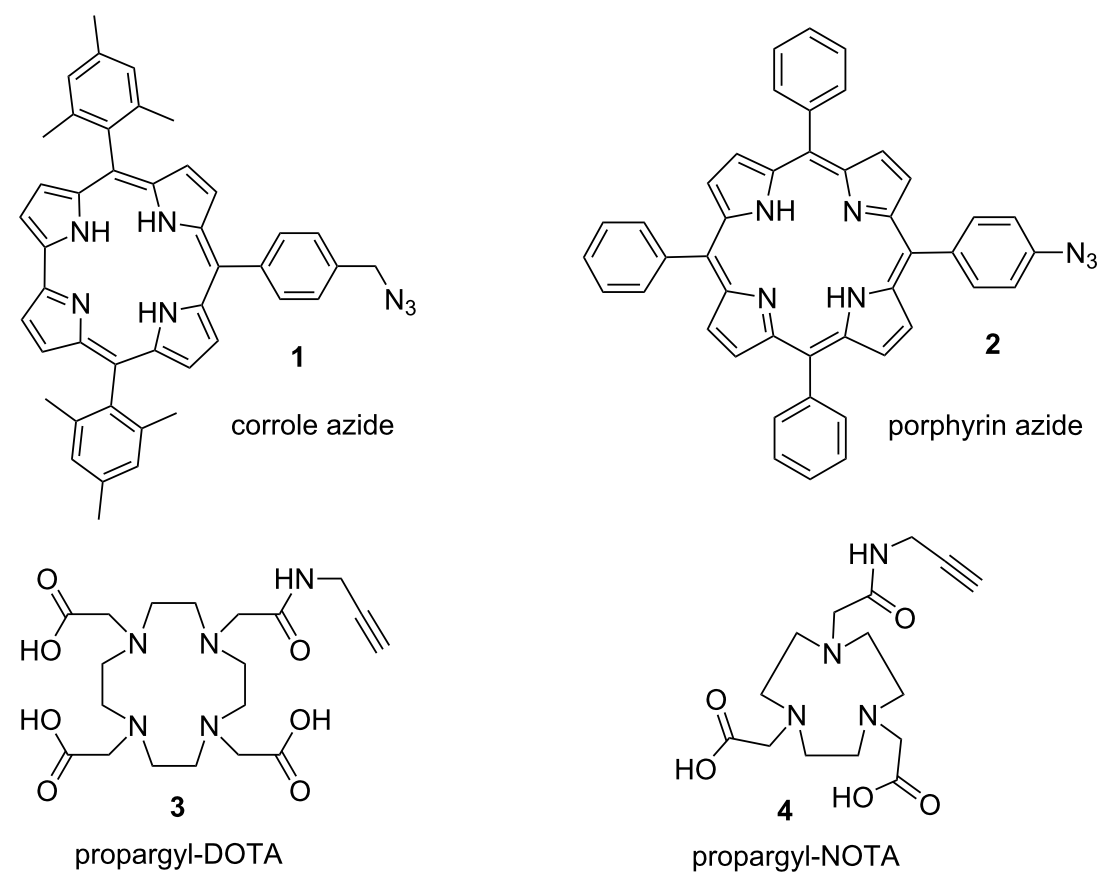

Figure 1: Selected ligands for the copper(I)-catalyzed Huisgen cycloaddition. 
phyrins as PET probes. $\mathrm{Cu}-\mathrm{NOTA}$ is significantly more inert in acidic conditions compared to $\mathrm{Cu}$-DOTA, which usually decomplexed within few minutes. ${ }^{64} \mathrm{Cu}^{2+}$-NOTA is considered as better PET agent, with regard to its in vivo stability [18]. Porphyrins are also excellent macrocyclic ligands forming highly stable transition metal complexes making them efficient delivery vehicles for radioisotopes. The radioactive ${ }^{64} \mathrm{Cu}^{2+}$-porphyrin is known to be extremely stable. Shi et al. [19] have described an easy and efficient radiolabeling of the porphyrin macroring with ${ }^{64} \mathrm{Cu}$. Mukai et al. [20] have reported the successful synthesis of ${ }^{64} \mathrm{Cu}$-chelated porphyrin photosensitizers and a tumor targeting peptide. To the best of our knowledge, no previous example of the preparation of radioligand ${ }^{64} \mathrm{Cu}$ corrole has been so far reported. Due to their easy copper insertion [21], corroles can be considered as really good candidates for the complexation of ${ }^{64} \mathrm{Cu}$. In solution, free-base corroles are more sensitive than the analog porphyrins and may decompose to some open biliverdin-type structures upon air and light exposure. However, metallocorroles are generally more stable than their free-base form [21].

Gallium-68. NOTA [22] and DOTA [23] have been reported to form a stable complex with gallium(III) and those two ligands are widely used in the preparation of ${ }^{68} \mathrm{Ga}$-based PET probes. Advantageously, Ga complexes of porphyrins and corroles are known to be very stable allowing possible PET imaging applications [24].

Indium-111. One major isotope used within DOTA-SPECT agents is ${ }^{111}$ In (displaying a half-live of 67 hours). It should be noted that the well-established ${ }^{111}$ In-DOTA is in vivo robust [25] and many articles have been reported in the literature highly supporting the potential convenient utility of radiolabeled ${ }^{111}$ In-NOTA [26]. Unlike the corrole macrocycle, indium(III) porphyrins can be prepared [27].

We wish to report herein (Scheme 1) the convenient synthesis of various multimodal ligands.

Those complexes, incorporating one porphyrin or one corrole moiety on one side and one DOTA or NOTA-like macrocycle on the other side, have been easily linked by microwave azide-alkyne 1,3-dipolar cycloaddition.

The preliminary relaxivity study of these heterobimetallic complexes was also investigated for potential MRI applications.

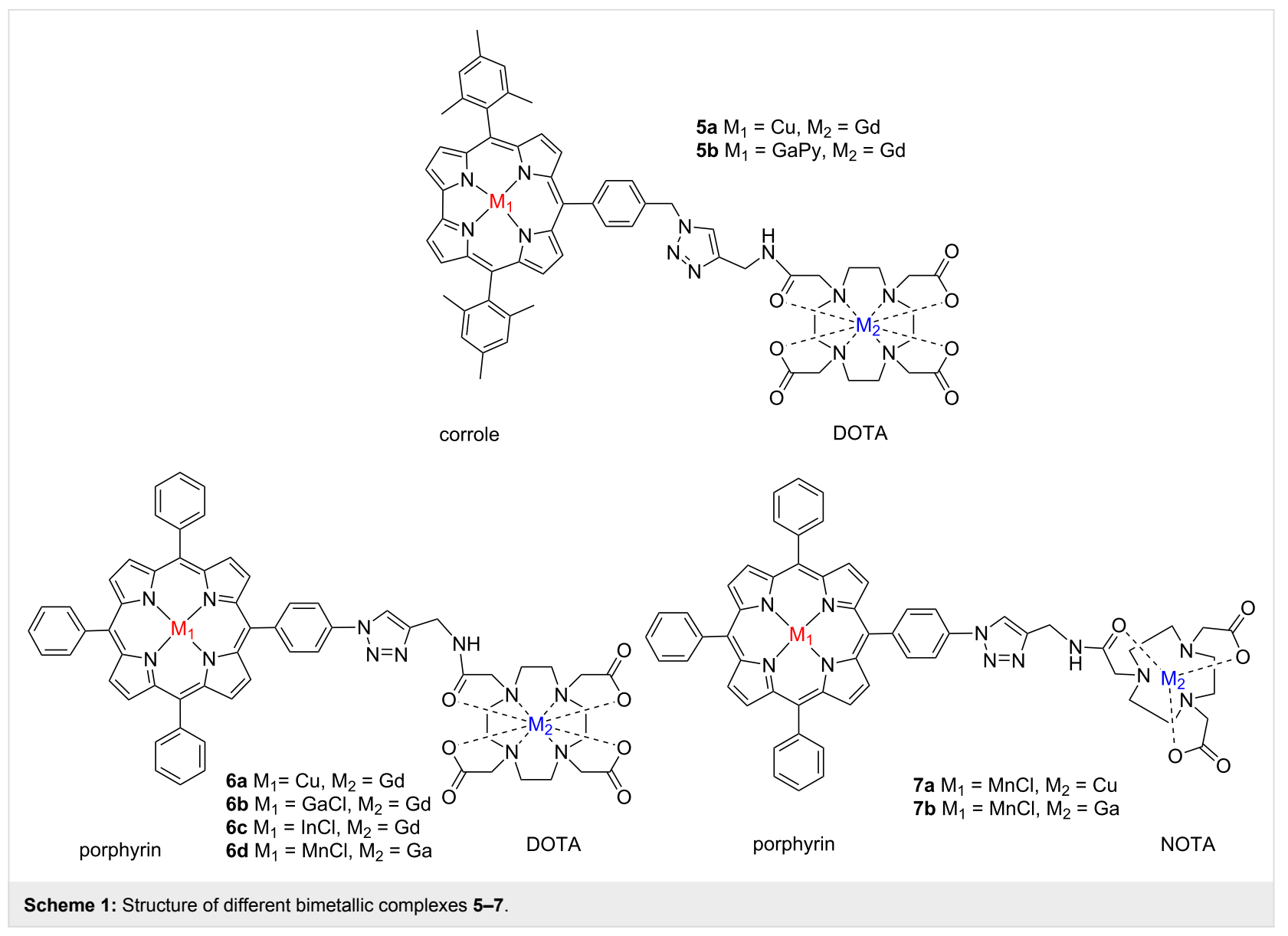




\section{Results and Discussion}

We first wish to report a "library" of azido and alkyne derivatives to further interconnect by microwave-assisted click reaction.

\section{Azidocorroles/porphyrins}

Azidocorrole 1 [9] was obtained by the condensation of the corresponding meso-mesityl-substituted dipyrromethane with 4-azidobenzaldehyde in the presence of a catalytic amount of trifluoroacetic acid, followed by oxidation under the action of DDQ. $\mathrm{Cu}$ and $\mathrm{Ga}$ complexes were prepared by the strategy outlined in Scheme 2.

The insertion of $\mathrm{Cu}$ into corrole $\mathbf{1}$ was easily achieved with $\mathrm{Cu}(\mathrm{OAc})_{2} \cdot \mathrm{H}_{2} \mathrm{O}$ in THF during $15 \mathrm{~min}$. To obtain the gallium corrole $\mathbf{8 b}$, free-base azidocorrole $\mathbf{1}$ was dissolved in a solution of $\mathrm{GaCl}_{3}$ in pyridine and then refluxed for $1.5 \mathrm{~h}$ as previously described [28]. Corroles 8a and $\mathbf{8 b}$ were prepared and characterized by ${ }^{1} \mathrm{H}$ NMR, HRMS and UV-vis absorption spectroscopy.
Different metal ions were introduced inside the porphyrin core $\mathbf{2}$, namely copper, gallium, indium and manganese. For the synthesis of copper porphyrin 9a, compound $\mathbf{2}$ [10] was reacted with $\mathrm{Cu}(\mathrm{OAc})_{2}$. The gallium complex of porphyrin 2 was prepared starting from $\mathrm{GaCl}_{3}$ in refluxing $\mathrm{AcOH}$. The insertion of indium into porphyrin 2 was achieved by heating with $\mathrm{InCl}_{3}$ salt in $\mathrm{AcOH}$. Finally, manganese chloride and $\mathbf{2}$ were dissolved in benzonitrile and then refluxed to yield 9d. The target metalated porphyrins $\mathbf{9 a - d}$ were isolated in moderate to good yields ranging from 51 to $82 \%$ and were fully characterized by ${ }^{1} \mathrm{H}$ NMR, MS (MALDI-TOF) and HRMS (ESI) spectrometry.

\section{Alkynyl DOTA/NOTA}

In a second step, the successful preparation of azidocorroles and porphyrins allows us to study their reactivity with different alkynes. To this end, a series of DOTA/NOTA complexes carrying alkyne reactive units were synthesized (Scheme 3).

DOTA carrying a propargylamido functionality $\mathbf{3}$ was prepared according to a literature procedure starting from commercially

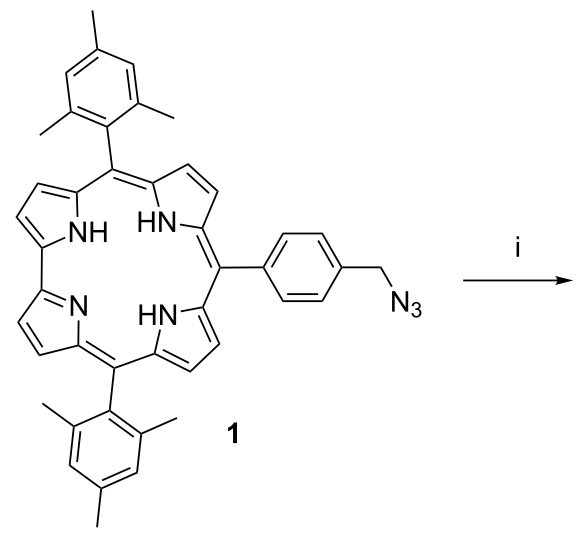

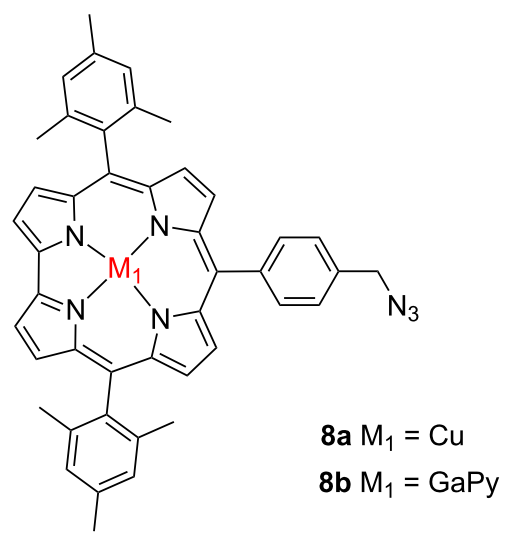<smiles></smiles>

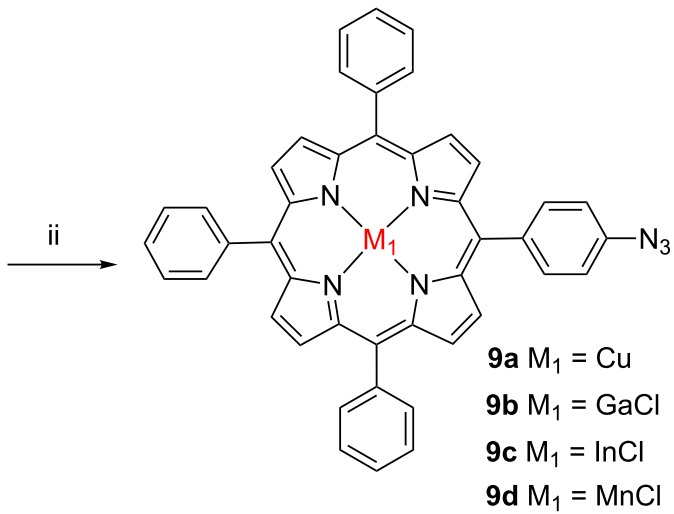

Scheme 2: Synthesis of $\mathbf{8 a}, \mathbf{b}$ and $\mathbf{9 a - d}$. (i) for $\mathbf{8 a}$ : THF, $\mathrm{N}_{2}, \mathrm{Cu}(\mathrm{OAc})_{2} \cdot \mathrm{H}_{2} \mathrm{O}$, rt $15 \mathrm{~min}$; for $\mathbf{8 b}: \mathrm{GaCl}_{3} 0.114 \mathrm{M}$ in dry pyridine, reflux $1.5 \mathrm{~h}$. (ii) for $\mathbf{9 a}$ : $\mathrm{CHCl}_{3} / \mathrm{MeOH}, \mathrm{Cu}(\mathrm{OAc})_{2} \cdot \mathrm{H}_{2} \mathrm{O}$, reflux $12 \mathrm{~h}$; for $9 \mathrm{~b}: \mathrm{GaCl}_{3}, \mathrm{AcOH}, \mathrm{AcONa}$, reflux overnight; for $9 \mathrm{c}$ : InCl $, \mathrm{AcOH}, \mathrm{AcONa}$, reflux $18 \mathrm{~h}$; for $9 \mathrm{~d}$ : $\mathrm{MnCl}_{2} \cdot 4 \mathrm{H}_{2} \mathrm{O}$, benzonitrile, reflux $1.5 \mathrm{~h}$. 


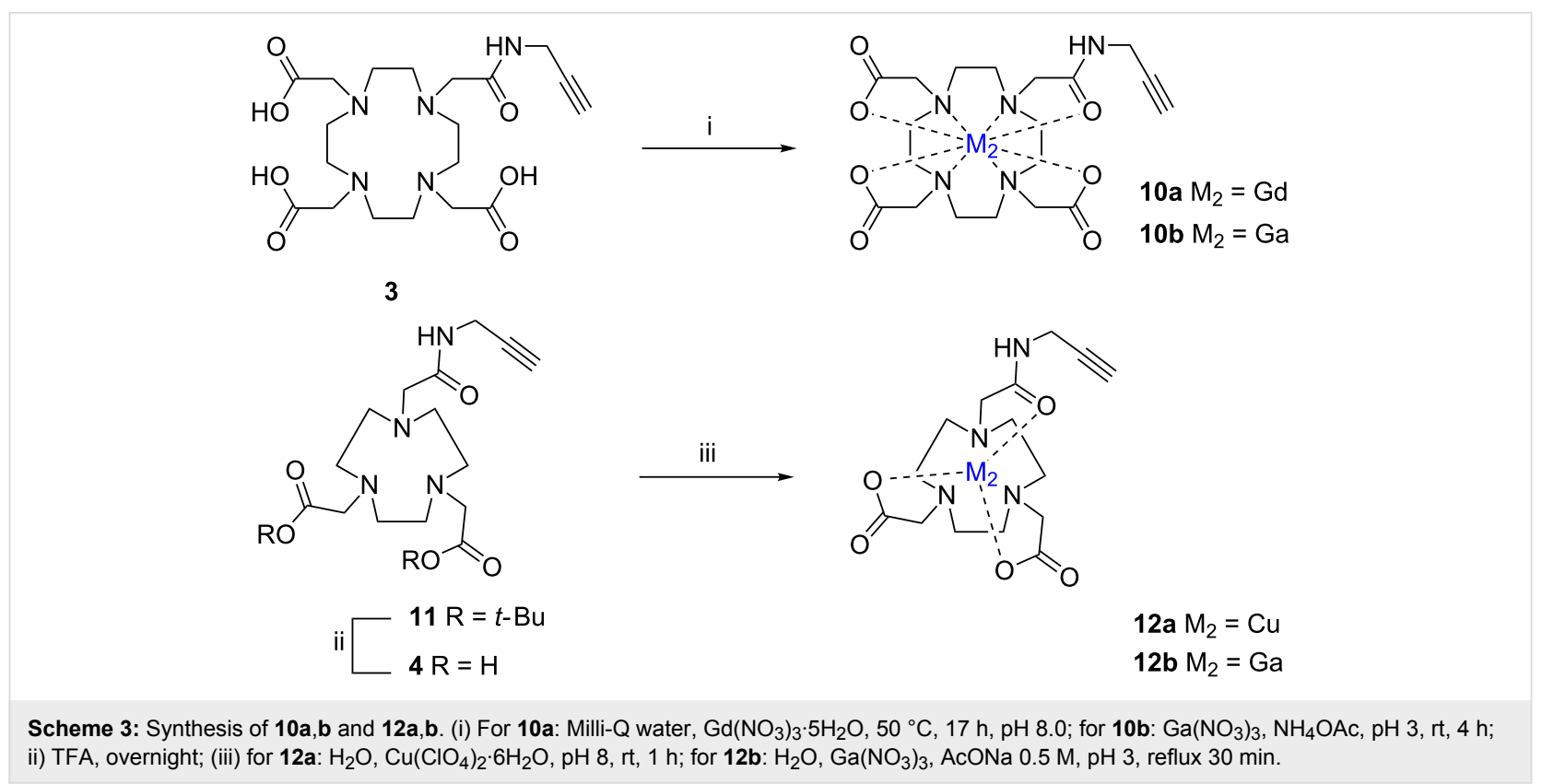

available propargylamido-DOTA-tris $(t-\mathrm{Bu})$ ester [29]. Complexation of $\mathbf{3}$ with a lanthanide was previously described by Borbas et al. [30]. Gd(DOTA) complex 10a, containing a pendant terminal alkyne group, was prepared by variation of a known procedure [29,31], as shown in Scheme 3. The complex was obtained by precipitation from a concentrated methanolic solution by slow addition of diethyl ether. Compound 3 was reacted with $\mathrm{Ga}\left(\mathrm{NO}_{3}\right)_{3}$ to lead to $\mathbf{1 0 b}$ in $94 \%$ yield after flash chromatography. The IR spectrum of $\mathbf{1 0 b}$ exhibits the characteristic band of the carbonyl stretching vibration from $1722 \mathrm{~cm}^{-1}$ to $1656 \mathrm{~cm}^{-1}$, which clearly demonstrates the complexation of $\mathrm{Ga}^{3+}$ ions with the carboxylic acid groups of ligand 3.

Another macrocycle commonly used in medical imaging studies is the NOTA ligand, which is usually preferred to DOTA to chelate e.g. $\mathrm{Cu}^{2+}$. Propargyl-NOTA $(t-\mathrm{Bu})_{2} \mathbf{1 1}$ (commercially available) was first dissolved in trifluoroacetic acid (TFA) and stirred at room temperature overnight. A brown oil was obtained upon concentration. The residue was then purified by flash chromatography. Chelation of $\mathrm{Cu}^{2+}$ with propargyl NOTA 4 was performed in aqueous solution by $\mathrm{Cu}\left(\mathrm{ClO}_{4}\right)_{2} \cdot 6 \mathrm{H}_{2} \mathrm{O}$. Purification of $\mathrm{Cu}$ propargyl NOTA was performed by precipitation in diethyl ether in $94 \%$ yield. To prepare the gallium complex 12b, propargyl NOTA 4 and $\mathrm{Ga}\left(\mathrm{NO}_{3}\right)_{3}$ were dissolved, at $\mathrm{pH} 3$, in water and then refluxed for $30 \mathrm{~min}$. The $\mathrm{pH}$ of the reaction was adjusted $(\mathrm{AcONa} 0.5 \mathrm{M})$, in each case, to optimize the complexation kinetic (e.g., $\mathrm{pH}$ fix at 7 for $\mathrm{Cu}^{2+}$ and $\mathrm{pH}$ fix at 3 for $\mathrm{Ga}^{3+}$ ). The isolated copper and gallium NOTA derivatives 12a,b were characterized by high-resolution mass spectrometry.

\section{Scope of the cycloaddition reaction}

Over the past decade, click chemistry has been applied to the synthesis of a wide variety of radiolabeled imaging agents with increasing frequency [7,32]. A methodology for the click reaction of azidocorrole or porphyrin has been recently developed in our laboratory $[28,33]$. We thus used similar conditions. The reactions were carried out in DMF, using excess of the alkyne derivative in the presence of the azido counterpart, $\mathrm{CuI}$ and DIPEA. A very slow progress of the reaction was observed by TLC during the synthesis of $\mathbf{5 a}$ at room temperature. Thus the reaction mixture was heated to $50{ }^{\circ} \mathrm{C}$. Consumption of the azidocorrole 8a (starting default reactant) was observed by TLC, in 4 hours. Unfortunately, increasing the temperature did not speed up the kinetic of the reaction (e.g. decrease the reaction time). Instead, degradation of corrole 8a was observed upon time. An optimization of the reaction conditions was thus carried out to find reaction conditions as much as possible compatible with the future use of radioactive isotopes possessing short life times (e.g. $\mathrm{Cu}^{2+}$ and $\mathrm{In}^{3+}$ ). Microwave irradiation, known to accelerate the polarization of the starting materials to promote the reactions, was investigated. A mixture of azidocorrole 8a, Gd propargyl DOTA 10a, CuI, DIPEA and DMF were irradiated in a quartz vessel using a microwave oven at $60 \mathrm{~W}$ for $30 \mathrm{~min}$. After evaporation of DMF and DIPEA, the obtained precipitate was washed with dichloromethane (to remove any starting azido corrole $\mathbf{8 a}$ ), washed with water (to remove excess propargyl DOTA 10a) then washed with ammonia aqueous solution $5.5 \%$ (to remove $\mathrm{Cu}\left(\mathrm{NH}_{3}\right)_{2}$ complex). The successful formation of the $\mathrm{Cu}$ corrole/Gd DOTA complex 5a was confirmed by HRMS (ESI) mass spectrometry by the presence of the pseudo-molecular ion peak $[\mathrm{M}+\mathrm{H}]^{+}$at 
1322.3695 (4.9 ppm deviation with respected to calculated mass). The same procedure was adopted for the preparation of bimetallic compounds 5-7 as shown in Table 1.

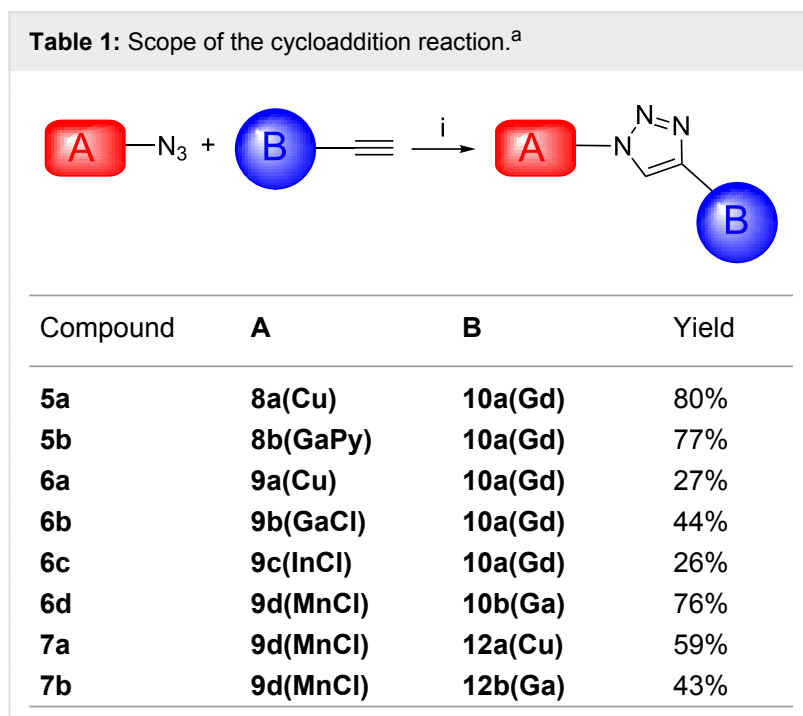

aReaction conditions: corrole/porphyrin complex: 1 equiv, coupling partner: DOTA/NOTA 1.5 equiv; Cul: 3 equiv, DIPEA: 5 equiv, DMF, microwave heating.

The reaction conditions used for all the reported examples were identical to those for $\mathbf{5 a}$, and the yields were from moderate to good. All the final products were characterized by HRMS, $\mathrm{UV}-\mathrm{vis}$ and IR spectroscopy.

\section{Relaxivity measurements}

The relaxivity measurements is a complementary method for the complete characterization of a paramagnetic complex. As described by Shu [34], the ability of proton relaxation enhancement of a paramagnetic compound is expressed by the term relaxivity $r_{i}$ as denoted in Equation 1

$$
\left(1 / T_{\mathrm{i}}\right)_{\mathrm{obs}}=\left(1 / T_{\mathrm{i}}\right)_{\mathrm{dia}}+r_{\mathrm{i}} \cdot[\mathrm{M}], \text { with } \mathrm{i}=1,2
$$

where $1 / T_{1}$ and $1 / T_{2}$ are, respectively, the longitudinal and transverse relaxation rates, $[\mathrm{M}]$ is the concentration of the paramagnetic species, $\left(1 / T_{\mathrm{i}}\right)_{\mathrm{obs}}$ and $\left(1 / T_{\mathrm{i}}\right)_{\mathrm{dia}}$ are defined as the observed relaxation rate of water proton in the presence and in the absence of the paramagnetic species, respectively. The relaxivities of compound 9d, 11a and 5-7 were measured at $0.47 \mathrm{~T}$ and $40{ }^{\circ} \mathrm{C}$. As shown in Table 2, Mn azidoporphyrin 9d and Gd propargyl-DOTA 10a exhibited similar relaxivities than DOTAREM contrast agent widely used in clinical practice $\left(r_{1}=3.5 \mathrm{mM}^{-1} \mathrm{~s}^{-1}\right.$ at $\left.20 \mathrm{MHz}, 37^{\circ} \mathrm{C}\right)$ [35]. In contrast, most of bimodal complexes 5-7 exhibited higher relaxivities than DOTAREM. The molecular weight of here described complexes is significantly higher than the commercially available DOTA derivatives, inducing a slower molecular tumbling known to have a key effect on the increase of the relaxivity [36].

\begin{tabular}{|ll}
\hline Table 2: Relaxivity measurements. \\
\hline Gd/Mn Complex & Relaxivity $r_{1}^{a}\left(\mathrm{mM}^{-1} \mathrm{~s}^{-1}\right)$ \\
\hline $\mathbf{9 d}$ & 2.0 \\
$\mathbf{1 0 a}$ & 2.2 \\
$\mathbf{5 a}$ & 9.2 \\
$\mathbf{5 b}$ & 6.3 \\
$\mathbf{6 b}$ & 8.2 \\
$\mathbf{6 c}$ & 11.6 \\
$\mathbf{7 a}$ & 3.4 \\
$\mathbf{7 b}$ & 5.7 \\
\hline
\end{tabular}

a20 $\mathrm{MHz}, 0.47 \mathrm{~T}, 40^{\circ} \mathrm{C}$.

\section{Conclusion}

Recent synthetic trategies using click chemistry have shown significant advantages over traditional procedures for the modular, rapid, clean, and efficient synthesis of potential radiopharmaceuticals. In this regard, click chemistry has already begun to revolutionize radiopharmaceutical chemistry. The method reported herein provided convenient and rapid access to bimetallic building blocks, opening the door for a wide range of applications in medical imaging.

In some cases, the requirement of a metal catalyst can be a complication. Therefore, we actually focus our researches on the development of catalyst-free click reactions using, e.g., cyclooctyne DOTA derivatives.

\section{Supporting Information}

\section{Supporting Information File 1}

Materials, methods and experimental procedures. ${ }^{1} \mathrm{H}$ NMR spectra of $8 \mathbf{a}, 9 \mathbf{b}, \mathbf{c}, \mathbf{4}, \mathbf{1 2 b}$. HRMS spectra of $8 \mathbf{a}, 9 \mathbf{a}-\mathbf{d}$, 10b, 4, 12a,b, 5a,b, 6a,d, 7a,b.

[http://www.beilstein-journals.org/bjoc/content/ supplementary/1860-5397-11-239-S1.pdf]

\section{Acknowledgements}

The "Centre National de la Recherche Scientifique" (ICMUB, UMR CNRS 6302) is gratefully thanked for financial support. Support was provided by the CNRS, the "Université de Bourgogne" and the "Conseil Régional de Bourgogne" through the 3MIM integrated project ("Marquage de Molécules par les Métaux pour l'Imagerie Médicale"). Fanny Picquet, Marie José 
Penouilh and Myriam Heydel are warmly acknowledged for technical support.

\section{References}

1. Jennings, L. E.; Long, N. J. Chem. Commun. 2009, 3511-3524. doi:10.1039/b821903f

2. Eggenspiller, A.; Michelin, C.; Desbois, N.; Richard, P.; Barbe, J.-M.; Denat, F.; Licona, C.; Gaiddon, C.; Sayeh, A.; Choquet, P.; Gros, C. P. Eur. J. Org. Chem. 2013, 6629-6643. doi:10.1002/ejoc.201300678

3. Gros, C. P.; Eggenspiller, A.; Nonat, A.; Barbe, J.-M.; Denat, F. Med. Chem. Commun. 2011, 2, 119-125. doi:10.1039/C0MD00205D

4. Vologdin, N.; Rolla, G. A.; Botta, M.; Tei, L. Org. Biomol. Chem. 2013, 11, 1683-1690. doi:10.1039/c2ob27200h

5. Ranyuk, E.; Lebel, R.; Bérubé-Lauzière, Y.; Klarskov, K.; Lecomte, R.; van Lier, J. E.; Guérin, B. Bioconjugate Chem. 2013, 24, 1624-1633. doi:10.1021/bc400257u

6. Park, J.-A.; Kim, J. Y.; Lee, Y. J.; Lee, W.; Lim, S. M.; Kim, T.-J.; Yoo, J.; Chang, Y.; Kim, K. M. ACS Med. Chem. Lett. 2013, 4, 216-219. doi:10.1021/ml3003499

7. Zeng, D.; Zeglis, B. M.; Lewis, J. S.; Anderson, C. J. J. Nucl. Med. 2013, 54, 829-832. doi:10.2967/jnumed.112.115550

8. Frullano, L.; Catana, C.; Benner, T.; Sherry, A. D.; Caravan, P. Angew. Chem., Int. Ed. 2010, 49, 2382-2384. doi:10.1002/anie.201000075

9. Barbe, J.-M.; Canard, G.; Brandès, S.; Guilard, R. Eur. J. Org. Chem. 2005, 4601-4611. doi:10.1002/ejoc.200500374

10. Flavin, K.; Chaur, M. N.; Echegoyen, L.; Giordani, S. Org. Lett. 2010, 12, 840-843. doi:10.1021/ol902939f

11. Sukerkar, P. A.; MacRenaris, K. W.; Townsend, T. R.; Ahmed, R. A.; Burdette, J. E.; Meade, T. J. Bioconjugate Chem. 2011, 22, 2304-2316. doi:10.1021/bc2003555

12. Radzki, S.; Giannotti, C. Inorg. Chim. Acta 1993, 205, 213-219. doi:10.1016/S0020-1693(00)85541-3

13. Drahoš, B.; Kubiček, V.; Bonnet, C. S.; Hermann, P.; Lukeš, I.; Tóth, E. Dalton Trans. 2011, 40, 1945-1951. doi:10.1039/c0dt01328e

14. Cheng, W.; Ganesh, T.; Martinez, F.; Lam, J.; Yoon, H.; Macgregor, R. B., Jr.; Scholl, T. J.; Cheng, H.-L. M.; Zhang, X.-a. JBIC, J. Biol. Inorg. Chem. 2014, 19, 229-235. doi:10.1007/s00775-013-1073-6

15. Cheng, W.; Haedicke, I. E.; Nofiele, J.; Martinez, F.; Beera, K.; Scholl, T. J.; Cheng, H.-L. M.; Zhang, X.-a. J. Med. Chem. 2014, 57, 516-520. doi:10.1021/jm401124b

16. Ferdani, R.; Stigers, D. J.; Fiamengo, A. L.; Wei, L.; Li, B. T. Y.; Golen, J. A.; Rheingold, A. L.; Weisman, G. R.; Wong, E. H.; Anderson, C. J. Dalton Trans. 2012, 41, 1938-1950. doi:10.1039/C1DT11743B

17. Hao, G.; Sun, X.; Do, Q. N.; Ocampo-Garcia, B.; Vilchis-Juárez, A.; Ferro-Flores, G.; De León-Rodriguez, L. M. Dalton Trans. 2012, 41, 14051-14054. doi:10.1039/c2dt31493b

18. Zhang, Y.; Hong, H.; Engle, J. W.; Bean, J.; Yang, Y.; Leigh, B. R.; Barnhart, T. E.; Cai, W. PLoS One 2011, 6, e28005. doi:10.1371/journal.pone.0028005

19. Shi, J.; Liu, T. W. B.; Chen, J.; Green, D.; Jaffray, D.; Wilson, B. C.; Wang, F.; Zheng, G. Theranostics 2011, 1, 363-370. doi:10.7150/thno/v01p0363

20. Mukai, H.; Wada, Y.; Watanabe, Y. Ann. Nucl. Med. 2013, 27 , 625-639. doi:10.1007/s12149-013-0728-2

21. Ngo, T. H.; Van Rossom, W.; Dehaen, W.; Maes, W. Org. Biomol. Chem. 2009, 7, 439-443. doi:10.1039/B819185A
22. Förster, C.; Schubert, M.; Pietzsch, H.-J.; Steinbach, J. Molecules 2011, 16, 5228-5240. doi:10.3390/molecules 16065228

23. Clarke, E. T.; Martell, A. E. Inorg. Chim. Acta 1991, 190, 37-46. doi:10.1016/S0020-1693(00)80229-7

24. Bryden, F.; Savoie, H.; Rosca, E. V.; Boyle, R. W. Dalton Trans. 2015, 44, 4925-4932. doi:10.1039/C4DT02949F

25. Duncan, J. R.; Stephenson, M. T.; Wu, H. P.; Anderson, C. J. Cancer Res. 1997, 57, 659-671.

26. Varasteh, Z.; Åberg, O.; Velikyan, I.; Lindeberg, G.; Sörensen, J.; Larhed, M.; Antoni, G.; Sandström, M.; Tolmachev, V.; Orlova, A. PLoS One 2013, 8, e81932. doi:10.1371/journal.pone.0081932

27. Dilworth, J. R.; Pascu, S. I.; Waghorn, P. A.; Vullo, D.; Bayly, S. R.; Christlieb, M.; Sun, X.; Supuran, C. T. Dalton Trans. 2015, 44, 4859-4873. doi:10.1039/C4DT03206C

28. Brizet, B.; Desbois, N.; Bonnot, A.; Langlois, A.; Dubois, A.; Barbe, J.-M.; Gros, C. P.; Goze, C.; Denat, F.; Harvey, P. D. Inorg. Chem. 2014, 53, 3392-3403. doi:10.1021/ic402798f

29. Fernández-Trillo, F.; Pacheco-Torres, J.; Correa, J.; Ballesteros, P.; Lopez-Larrubia, P.; Cerdán, S.; Riguera, R.; Fernandez-Megia, E. Biomacromolecules 2011, 12, 2902-2907. doi:10.1021/bm2004466

30. Szijjártó, C.; Pershagen, E.; Borbas, K. E. Dalton Trans. 2012, 41, 7660-7669. doi:10.1039/c2dt30569k

31. Song, Y.; Kohlmeir, E. K.; Meade, T. J. J. Am. Chem. Soc. 2008, 130 , 6662-6663. doi:10.1021/ja0777990

32. Mirfeizi, L.; Campbell-Verduyn, L.; Dierckx, R. A.; Feringa, B. L.; Elsinga, P. H. Curr. Org. Chem. 2013, 17, 2108-2118. doi:10.2174/13852728113179990103

33. Eggenspiller, A.; Takai, A.; El-Khouly, M. E.; Ohkubo, K.; Gros, C. P.; Bernhard, C.; Goze, C.; Denat, F.; Barbe, J.-M.; Fukuzumi, S. J. Phys. Chem. A 2012, 116, 3889-3898. doi:10.1021/jp300415a

34. Shu, C.-Y.; Gan, L.-H.; Wang, C.-R.; Pei, X.-I.; Han, H.-b. Carbon 2006, 44, 496-500. doi:10.1016/j.carbon.2005.08.016

35. Laurent, S.; Vander Elst, L.; Muller, R. N. Contrast Media Mol. Imaging 2006, 1, 128-137. doi:10.1002/cmmi. 100

36. Caravan, P. Chem. Soc. Rev. 2006, 35, 512-523. doi:10.1039/b510982p

\section{License and Terms}

This is an Open Access article under the terms of the Creative Commons Attribution License (http://creativecommons.org/licenses/by/2.0), which permits unrestricted use, distribution, and reproduction in any medium, provided the original work is properly cited.

The license is subject to the Beilstein Journal of Organic Chemistry terms and conditions: (http://www.beilstein-journals.org/bjoc)

The definitive version of this article is the electronic one which can be found at: doi:10.3762/bjoc.11.239 